\title{
On the potential application of DFT methods in predicting the interaction-induced electric properties of molecular complexes. Molecular H-bonded chains as a case of study
}

\author{
Agnieszka Zawada • Anna Kaczmarek-Kędziera • \\ Wojciech Bartkowiak
}

Received: 4 September 2011 / Accepted: 14 November 2011 /Published online: 17 December 2011

(C) The Author(s) 2011. This article is published with open access at Springerlink.com

\begin{abstract}
A detailed analysis of the selected DFT functionals for the calculations of interaction-induced dipole moment, polarizability and first-order hyperpolarizability has been carried out. The hydrogen-bonded model chains consisting of $\mathrm{HF}, \mathrm{H}_{2} \mathrm{CO}$ and $\mathrm{H}_{3} \mathrm{~N}$ molecules have been chosen as a case study. The calculations of the components of the static electric properties using the diffuse Dunning's basis set (aug-cc-pVDZ) have been performed employing different types of density functionals (B3LYP, LC-BLYP, PBE0, M06-2X and CAM-B3LYP). Obtained results have been compared with those gained at the $\operatorname{CCSD}(\mathrm{T})$ level of theory. The counterpoise correction scheme, namely site-site function counterpoise, has been applied in order to eliminate basis set superposition error. The performed tests allow to conclude that the DFT functionals can provide a useful tool for prediction of the interaction-induced electric properties, however a caution has to be urged to their decomposition to the two- and many-body terms.
\end{abstract}

Keywords Density functional theory · Hydrogen bond . (Hyper) polarizability · Interaction-induced electric property . Many-body effects

\footnotetext{
A. Zawada $(\triangle) \cdot$ W. Bartkowiak

Institute of Physical and Theoretical Chemistry,

University of Technology,

Wybrzeże Wyspiańskiego 27,

50-370 Wroclaw, Poland

e-mail: agnieszka.zawada@pwr.wroc.pl

A. Kaczmarek-Kędziera

Faculty of Chemistry, Nicolaus Copernicus University,

Gagarina 7,

87-100 Torun, Poland
}

\section{Introduction}

Intermolecular interactions can significantly modify the properties of the investigated systems. Therefore, they continuously remain of interest for non-linear optics, nanoelectronics, biotechnology and many other fields of science. From the point of view of material science, interaction-induced electric properties for hydrogen-bonded systems could be of particular importance. However, systems that become relevant as novel materials are usually composed of more than several light atoms and therefore high-level calculations of their properties are prohibitively expensive. Thus, cheaper alternatives are sought. One of them appears to be the density functional theory (DFT). The great abundance of the various available DFT functionals allows to extend the investigations to the systems of hundreds of atoms and the wide range of analyzed properties.

It is known that the molecular electric properties can be reproduced by DFT methods with good accuracy [1-12]. However, one should bear in mind that for several classes of systems of importance to the non-linear optics, for instance long $\pi$ conjugated polymer chains as well as push-pull systems with significant charge transfer, such calculations lead to significant deterioration in the accuracy of the results [13-15]. Still, not much care has been devoted to the interaction-induced increments to dipole moments and (hyper)polarizabilities calculated beyond the wave function theory. Sparse data regard mostly rare gas heterodiatoms [16-19]. Only recently, various DFT functionals have been tested for the series of hydrogen-bonded dimers: water dimer, $\mathrm{HF}$ dimer and $\mathrm{H}_{2} \mathrm{CO} \ldots \mathrm{HF}$ [20]. Although there is no unambiguous answer to the question which functional is best for interaction-induced electric properties, it is quite easy to reproduce the $\operatorname{CCSD}(\mathrm{T})$ results for investigated systems with DFT methods with satisfactory accuracy [20]. Regarding the gathered information, further studies seem necessary in order to generalize such an observation. 
The aim of the present study is to verify the applicability of the DFT formalism also for the interaction-induced electric properties of the longer hydrogen-bonded chains. The HF linear chain, $\mathrm{H}_{2} \mathrm{CO}$ crystal structure and $\mathrm{H}_{3} \mathrm{~N} \ldots(\mathrm{HF})_{\mathrm{n}}$ complex are investigated up to five units in the system. The chosen structures were previously investigated at an angle of the many-body contributions to the (non)linear electric response with second order Møller-Plesset perturbation theory and the many-body interactions in these systems proved to be significant $[21,22]$.

The performance of the DFT functionals is tested against the $\operatorname{CCSD}(\mathrm{T})$ data that provide the reference level. In order to keep the consistency with the previous study [20], the same exchange-correlation functionals have been applied here: B3LYP [23-26] and PBE0 [27] as conventional hybrids, LC-BLYP [28] as a long-range corrected functional and M06-2X hybrid meta functional [29]. Additionally, this set was appended by the B3LYP long-range corrected modification (CAM-B3LYP) [30] for which we expect to improve the accuracy of the results toward reference data.

\section{Methodology}

The subject of the present study are hydrogen-bonded complexes, namely: linear $\mathrm{HF} \cdots(\mathrm{HF})_{n}$, crystalline $\mathrm{H}_{2} \mathrm{CO} \cdots\left(\mathrm{H}_{2} \mathrm{CO}\right)_{n}$ and linear $\mathrm{H}_{3} \mathrm{~N} \cdots(\mathrm{HF})_{n}$, for which $\mathrm{n}=1-4$. The structures of linear $\mathrm{HF} \cdots(\mathrm{HF})_{n}[31]$ and $\mathrm{H}_{3} \mathrm{~N} \cdots(\mathrm{HF})_{n}$ [21] chains have been obtained based on gas-phase monomer geometries optimized at the MP2/6-31G(d,p) level of theory. Moreover, the intermonomer distance which corresponds to the separation in the linear dimer has been optimized at the very same level of theory. On the other hand, the geometry of the $\mathrm{H}_{2} \mathrm{CO} \cdots\left(\mathrm{H}_{2} \mathrm{CO}\right)_{n}$ chain refers to that found in the formaldehyde crystal [32]. The analyzed molecular complexes of maximal size are presented in Fig. 1.
All calculations of the static electric molecular properties were carried out at the SCF-HF, MP2, CCSD(T), B3LYP, PBE0, LC-BLYP, M06-2X and CAM-B3LYP level of theory. Values of the electric dipole (hyper) polarizability tensors have been obtained using the finite field (FF) method [33, 34] by numerical differentiation of energy with respect to external electric field $(\mathrm{F})$. Relying on our previous research [21, 22] the electric field of the strength 0.001 a.u. has been chosen for further calculations to ensure the numerical stability of the FF procedure.

Interaction-induced properties $\Delta P$ for the investigated systems were obtained in a supermolecular manner:

$\Delta P=P_{12 \ldots n}-\sum_{i=1}^{n} P_{i}$,

where $P_{12 \ldots n}$ and $P_{i}$ stands for the magnitude of the property for the $n$-body system and its constituents, respectively. In order to make the consistent comparison of electric properties for the whole set of studied systems, the following values of the electric properties are discussed:

$|\mu|=\sqrt{\mu_{x}^{2}+\mu_{y}^{2}+\mu_{z}^{2}}$,

$\alpha_{0}=\frac{1}{3}\left(\alpha_{x x}+\alpha_{y y}+\alpha_{z z}\right)$

$\beta_{\mu}=\frac{\beta_{x} \mu_{x}+\beta_{y} \mu_{y}+\beta_{z} \mu_{z}}{|\mu|}$,

where

$\beta_{i}=\frac{3}{5} \cdot \sum_{j=x, y, z} \beta_{i j j}$

and the Kleinman symmetry is satisfied.

The values of static electric properties obtained within the supermolecular approach together with basis set of finite a
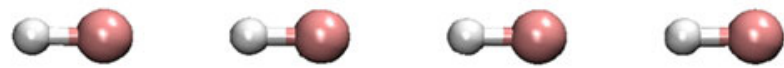

b
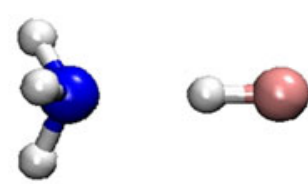

C

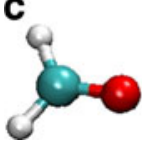

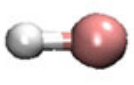
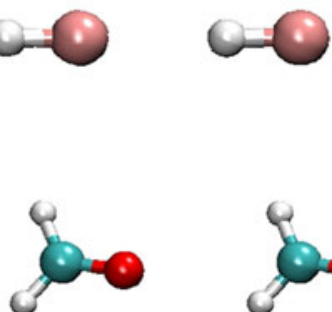

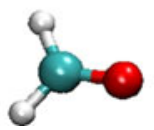

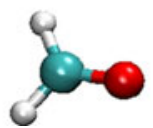

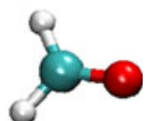

Fig. 1 Structure of investigated complexes of maximal length 
size might suffer from the basis set superposition error [35, 36]. Due to the fact that the first-order hyperpolarizability is the most sensitive to the choice of the basis set of all the properties analyzed here $[35,36]$, the correction for BSSE has been included according to the site-site function counterpoise scheme [37]. The total interaction-induced

Table 1 The values of the electric properties and their counterpoise corrected interaction-induced counterparts [a.u.] for the hydrogenbonded linear $\mathrm{HF} \cdots(\mathrm{HF})_{n}$ complexes. The subsequent columns contain the information about the chain length $\mathrm{n}$, the absolute value of the static dipole moment for the whole chain $|\mu|(0)$, the total interaction-induced counterpoise-corrected electric property $\Delta_{\text {total }} P^{C P}$ has been decomposed into:

$$
\begin{aligned}
\Delta_{\text {total }} P^{C P}= & \sum_{i<j} \Delta_{i j} P(1 \ldots n)+\sum_{i<j<k} \Delta_{i j k} P(1 \ldots n) \\
& +\ldots+\Delta_{1 \ldots n} P(1 \ldots n)
\end{aligned}
$$

dipole moment $\Delta|\mu|(0)$ and its contributions: two- and many-body, static polarizability $\alpha_{0}(0)$, the total interaction-induced polarizability $\Delta \alpha_{0}(0)$ and its two- and many-body components, first order hyperpolarizability $\beta_{\mu}(0)$, the total interaction-induced hyperpolarizability $\Delta \beta_{\mu}(0)$ and its

\begin{tabular}{|c|c|c|c|c|c|c|c|c|c|c|c|c|c|}
\hline \multirow[b]{2}{*}{$\mathrm{n}$} & & \multirow[t]{2}{*}{$|\mu|(0)$} & \multicolumn{3}{|l|}{$\Delta|\mu|(0)$} & \multirow[t]{2}{*}{$\alpha_{0}(0)$} & \multicolumn{3}{|c|}{$\Delta \alpha_{0}(0)$} & \multirow[t]{2}{*}{$\beta_{\mu}(0)$} & \multicolumn{3}{|c|}{$\Delta \beta_{\mu}(0)$} \\
\hline & & & Total & 2-body & M-body & & Total & 2-body & M-body & & Total & 2-body & M-body \\
\hline & \multicolumn{13}{|c|}{$\operatorname{CCSD}(\mathrm{T})$} \\
\hline 1 & & 1.5858 & 0.1730 & 0.1730 & - & 10.000 & 0.048 & 0.048 & - & -11.67 & 4.32 & 4.32 & - \\
\hline 2 & & 2.4985 & 0.3789 & 0.3619 & 0.0170 & 15.139 & 0.177 & 0.119 & 0.058 & -11.65 & 11.40 & 9.45 & 1.95 \\
\hline 3 & & 3.4218 & 0.5952 & 0.5554 & 0.0398 & 20.305 & 0.334 & 0.194 & 0.140 & -10.63 & 19.64 & 14.79 & 4.85 \\
\hline 4 & & 4.3494 & 0.8159 & 0.7510 & 0.0649 & 25.482 & 0.503 & 0.270 & 0.233 & -9.16 & 28.37 & 20.21 & 8.16 \\
\hline \multicolumn{14}{|c|}{ MP2 } \\
\hline 1 & & 1.5982 & 0.1739 & 0.1739 & - & 10.048 & 0.034 & 0.034 & - & -10.97 & 4.18 & 4.18 & - \\
\hline 2 & & 2.5176 & 0.3810 & 0.3640 & 0.0170 & 15.201 & 0.146 & 0.090 & 0.056 & -10.61 & 11.28 & 9.45 & 1.83 \\
\hline 3 & & 3.4477 & 0.5985 & 0.5589 & 0.0396 & 20.379 & 0.284 & 0.149 & 0.135 & -9.43 & 19.31 & 14.83 & 4.48 \\
\hline 4 & & 4.3820 & 0.8203 & 0.7557 & 0.0646 & 25.568 & 0.434 & 0.210 & 0.224 & -7.83 & 27.80 & 20.29 & 7.51 \\
\hline \multicolumn{14}{|c|}{ SCF-HF } \\
\hline 1 & & 1.6931 & 0.1677 & 0.1677 & - & 8.893 & 0.019 & 0.019 & - & -9.61 & 3.17 & 3.17 & - \\
\hline 2 & & 2.6527 & 0.3648 & 0.3509 & 0.0139 & 13.432 & 0.094 & 0.055 & 0.039 & -10.49 & 8.12 & 6.97 & 1.15 \\
\hline 3 & & 3.6216 & 0.5711 & 0.5388 & 0.0323 & 17.989 & 0.188 & 0.094 & 0.094 & -10.89 & 13.62 & 10.85 & 2.77 \\
\hline 4 & & 4.5942 & 0.7812 & 0.7286 & 0.0526 & 22.555 & 0.290 & 0.134 & 0.156 & -11.06 & 19.36 & 14.76 & 4.60 \\
\hline \multicolumn{14}{|c|}{ B3LYP } \\
\hline 1 & & 1.5976 & 0.1827 & 0.1827 & - & 10.458 & 0.096 & 0.096 & - & -12.03 & 3.44 & 3.44 & - \\
\hline 2 & & 2.5251 & 0.4018 & 0.3818 & 0.0200 & 15.854 & 0.277 & 0.211 & 0.066 & -10.49 & 11.86 & 8.08 & 3.78 \\
\hline 3 & & 3.4642 & 0.6323 & 0.5858 & 0.0465 & 21.280 & 0.490 & 0.327 & 0.163 & -7.14 & 22.17 & 12.71 & 9.46 \\
\hline 4 & & 4.4079 & 0.8674 & 0.7918 & 0.0756 & 26.720 & 0.718 & 0.445 & 0.273 & -3.17 & 33.29 & 18.03 & 15.26 \\
\hline \multicolumn{14}{|c|}{ LC-BLYP } \\
\hline 1 & & 1.6152 & 0.1857 & 0.1857 & - & 10.833 & 0.081 & 0.081 & - & -9.33 & 5.00 & 5.00 & - \\
\hline 2 & & 2.5546 & 0.4087 & 0.3884 & 0.0203 & 16.423 & 0.259 & 0.182 & 0.077 & -5.99 & 14.40 & 11.55 & 2.85 \\
\hline 3 & & 3.5060 & 0.6436 & 0.5961 & 0.0475 & 22.046 & 0.472 & 0.287 & 0.185 & -1.24 & 25.47 & 18.33 & 7.14 \\
\hline 4 & & 4.4624 & 0.8834 & 0.8059 & 0.0775 & 27.683 & 0.702 & 0.392 & 0.310 & 4.19 & 37.30 & 25.28 & 12.02 \\
\hline \multicolumn{14}{|c|}{ PBE0 } \\
\hline 1 & & 1.5989 & 0.1791 & 0.1791 & - & 10.237 & 0.101 & 0.101 & - & -11.14 & 3.69 & 3.69 & - \\
\hline 2 & & 2.5236 & 0.3934 & 0.3743 & 0.0191 & 15.521 & 0.283 & 0.221 & 0.062 & -9.72 & 11.45 & 8.11 & 3.34 \\
\hline 3 & & 3.4596 & 0.6189 & 0.5743 & 0.0446 & 20.835 & 0.497 & 0.343 & 0.154 & -6.76 & 21.41 & 13.39 & 8.02 \\
\hline 4 & & 4.4001 & 0.8488 & 0.7762 & 0.0726 & 26.163 & 0.724 & 0.466 & 0.258 & -3.20 & 31.80 & 18.42 & 13.38 \\
\hline \multicolumn{14}{|c|}{ M06-2X } \\
\hline 1 & & 1.6097 & 0.1752 & 0.1752 & - & 9.870 & 0.096 & 0.096 & - & -8.97 & 3.09 & 3.09 & - \\
\hline 2 & & 2.5363 & 0.3841 & 0.3661 & 0.0180 & 14.958 & 0.268 & 0.214 & 0.054 & -7.65 & 9.90 & 7.09 & 2.81 \\
\hline 3 & & 3.4735 & 0.6035 & 0.5617 & 0.0418 & 20.074 & 0.469 & 0.335 & 0.134 & -5.02 & 18.10 & 11.69 & 6.41 \\
\hline 4 & & 4.4151 & 0.8273 & 0.7593 & 0.0680 & 25.202 & 0.682 & 0.458 & 0.224 & -1.76 & 26.96 & 15.99 & 10.97 \\
\hline \multicolumn{14}{|c|}{ CAM-B3LYP } \\
\hline 1 & & 1.6161 & 0.1814 & 0.1814 & - & 10.355 & 0.079 & 0.079 & - & -10.15 & 4.22 & 4.22 & - \\
\hline 2 & & 2.5516 & 0.3984 & 0.3793 & 0.0191 & 15.691 & 0.243 & 0.177 & 0.066 & -8.15 & 12.63 & 10.06 & 2.57 \\
\hline 3 & & 3.4985 & 0.6267 & 0.5821 & 0.0446 & 21.055 & 0.440 & 0.278 & 0.162 & -4.76 & 22.66 & 16.28 & 6.38 \\
\hline 4 & & 4.4500 & 0.8595 & 0.7869 & 0.0726 & 26.434 & 0.650 & 0.380 & 0.270 & -0.78 & 32.94 & 21.24 & 11.70 \\
\hline
\end{tabular}
two- and many-body components 
Table 2 The values of the electric properties and their counterpoise corrected interaction-induced counterparts [a.u.] for the hydrogenbonded linear $\mathrm{H}_{3} \mathrm{~N} \cdots(\mathrm{HF})_{n}$ complexes. The subsequent columns contain the information about the chain length $\mathrm{n}$, the absolute value of the static dipole moment for the whole chain $|\mu|(0)$, the total interaction-induced dipole moment $\Delta|\mu|(0)$ and its contributions: two- and many-body, static polarizability $\alpha_{0}(0)$, the total interaction-induced polarizability $\Delta \alpha_{0}(0)$ and its two- and many-body components, first order hyperpolarizability $\beta_{\mu}(0)$, the total interaction-induced hyperpolarizability $\Delta \beta_{\mu}(0)$ and its two- and many-body components

\begin{tabular}{|c|c|c|c|c|c|c|c|c|c|c|c|c|}
\hline \multirow[b]{2}{*}{$n$} & \multirow[t]{2}{*}{$|\mu|(0)$} & \multicolumn{3}{|l|}{$\Delta|\mu|(0)$} & \multirow[t]{2}{*}{$\alpha_{0}(0)$} & \multicolumn{3}{|l|}{$\Delta \alpha_{0}(0)$} & \multirow[t]{2}{*}{$\beta_{\mu}(0)$} & \multicolumn{3}{|l|}{$\Delta \beta_{\mu}(0)$} \\
\hline & & Total & 2-body & M-body & & Total & 2-body & M-body & & Total & 2-body & M-body \\
\hline \multicolumn{13}{|c|}{$\operatorname{CCSD}(\mathrm{T})$} \\
\hline 1 & 1.7256 & 0.4294 & 0.4294 & - & 18.366 & -0.693 & -0.693 & - & -39.35 & -8.38 & -8.38 & - \\
\hline 2 & 2.6984 & 0.6948 & 0.6443 & 0.0505 & 23.640 & -0.436 & -0.538 & 0.102 & -25.03 & 14.29 & 13.37 & 0.92 \\
\hline 3 & 3.6379 & 0.9273 & 0.8434 & 0.0839 & 28.875 & -0.214 & -0.451 & 0.237 & -17.02 & 29.66 & 22.13 & 7.53 \\
\hline 4 & 4.5714 & 1.1538 & 1.0410 & 0.1128 & 34.076 & -0.021 & -0.372 & 0.351 & -12.91 & 41.19 & 28.81 & 12.38 \\
\hline \multicolumn{13}{|c|}{ MP2 } \\
\hline 1 & 1.7368 & 0.4271 & 0.4271 & - & 18.415 & -0.770 & -0.770 & - & -39.61 & -9.85 & -9.85 & - \\
\hline 2 & 2.7159 & 0.6930 & 0.6436 & 0.0494 & 23.687 & -0.545 & -0.634 & 0.089 & -26.21 & 11.29 & 11.39 & -0.10 \\
\hline 3 & 3.6620 & 0.9263 & 0.8441 & 0.0822 & 28.928 & -0.348 & -0.562 & 0.214 & -18.79 & 25.60 & 20.22 & 5.38 \\
\hline 4 & 4.6022 & 1.1538 & 1.0430 & 0.1108 & 34.139 & -0.177 & -0.498 & 0.321 & -14.89 & 36.53 & 26.96 & 9.57 \\
\hline \multicolumn{13}{|c|}{ SCF-HF } \\
\hline 1 & 1.7939 & 0.3987 & 0.3987 & - & 16.655 & -0.621 & -0.621 & - & -23.72 & -16.77 & -16.77 & - \\
\hline 2 & 2.8031 & 0.6446 & 0.6045 & 0.0401 & 21.282 & -0.459 & -0.532 & 0.073 & -16.45 & 7.43 & 7.21 & 0.22 \\
\hline 3 & 3.7850 & 0.8636 & 0.7972 & 0.0664 & 25.881 & -0.325 & -0.484 & 0.159 & -13.23 & 16.47 & 13.17 & 3.30 \\
\hline 4 & 4.7624 & 1.0783 & 0.9889 & 0.0894 & 30.461 & -0.209 & -0.441 & 0.232 & -12.10 & 23.57 & 17.87 & 5.70 \\
\hline \multicolumn{13}{|c|}{ B3LYP } \\
\hline 1 & 1.7604 & 0.4575 & 0.4575 & - & 18.935 & -0.721 & -0.721 & - & -43.48 & -11.45 & -11.45 & - \\
\hline 2 & 2.7526 & 0.7407 & 0.6833 & 0.0574 & 24.497 & -0.382 & -0.483 & 0.101 & -18.93 & 21.84 & 23.24 & -1.40 \\
\hline 3 & 3.7094 & 0.9889 & 0.8930 & 0.0959 & 30.023 & -0.075 & -0.350 & 0.275 & -3.34 & 44.54 & 32.39 & 12.15 \\
\hline 4 & 4.6598 & 1.2305 & 1.1015 & 0.1290 & 35.500 & 0.190 & -0.256 & 0.446 & 5.74 & 61.27 & 38.43 & 22.84 \\
\hline \multicolumn{13}{|c|}{ LC-BLYP } \\
\hline 1 & 1.7999 & 0.4579 & 0.4579 & - & 19.100 & -0.750 & -0.750 & - & -33.61 & -13.74 & -13.74 & - \\
\hline 2 & 2.8026 & 0.7436 & 0.6879 & 0.0557 & 24.827 & -0.440 & -0.537 & 0.097 & -15.04 & 12.66 & 15.18 & -2.52 \\
\hline 3 & 3.7714 & 0.9958 & 0.9013 & 0.0945 & 30.533 & -0.149 & -0.416 & 0.267 & -2.17 & 32.25 & 26.10 & 6.15 \\
\hline 4 & 4.7342 & 1.2420 & 1.1133 & 0.1287 & 36.201 & 0.110 & -0.306 & 0.416 & 6.40 & 47.47 & 34.45 & 13.02 \\
\hline \multicolumn{13}{|c|}{ PBE0 } \\
\hline 1 & 1.7639 & 0.4572 & 0.4572 & - & 18.597 & -0.641 & -0.641 & - & -39.45 & -9.60 & -9.60 & - \\
\hline 2 & 2.7525 & 0.7346 & 0.6788 & 0.0558 & 24.049 & -0.297 & -0.397 & 0.100 & -17.41 & 20.46 & 21.90 & -1.44 \\
\hline 3 & 3.7059 & 0.9772 & 0.8842 & 0.0930 & 29.455 & 0.004 & -0.260 & 0.264 & -3.91 & 41.06 & 31.23 & 9.83 \\
\hline 4 & 4.6528 & 1.2135 & 1.0882 & 0.1253 & 34.816 & 0.265 & -0.132 & 0.397 & 3.92 & 55.90 & 37.61 & 18.29 \\
\hline \multicolumn{13}{|c|}{ M06-2X } \\
\hline 1 & 1.7679 & 0.4466 & 0.4466 & - & 18.054 & -0.594 & -0.594 & - & -32.85 & -11.90 & -11.90 & - \\
\hline 2 & 2.7543 & 0.7146 & 0.6633 & 0.0513 & 23.279 & -0.286 & -0.365 & 0.079 & -16.52 & 10.90 & 12.87 & -1.97 \\
\hline 3 & 3.7077 & 0.9500 & 0.8641 & 0.0859 & 28.467 & -0.016 & -0.227 & 0.211 & -6.65 & 26.41 & 20.61 & 5.80 \\
\hline 4 & 4.6552 & 1.1795 & 1.0637 & 0.1158 & 33.620 & 0.223 & -0.102 & 0.325 & -0.74 & 38.02 & 25.32 & 12.70 \\
\hline \multicolumn{13}{|c|}{ CAM-B3LYP } \\
\hline 1 & 1.7808 & 0.4493 & 0.4493 & - & 18.602 & -0.696 & -0.696 & - & -34.74 & -10.67 & -10.67 & - \\
\hline 2 & 2.7778 & 0.7272 & 0.6731 & 0.0541 & 24.078 & -0.396 & -0.497 & 0.101 & -16.46 & 15.27 & 15.76 & -0.49 \\
\hline 3 & 3.7414 & 0.9721 & 0.8814 & 0.0907 & 29.525 & -0.124 & -0.382 & 0.258 & -4.71 & 33.86 & 25.55 & 8.31 \\
\hline 4 & 4.6991 & 1.2111 & 1.0884 & 0.1227 & 34.932 & 0.116 & -0.275 & 0.391 & 2.53 & 47.70 & 31.84 & 15.86 \\
\hline
\end{tabular}


Table 3 The values of the electric properties and their counterpoise corrected interaction-induced counterparts [a.u.] for the hydrogenbonded crystalline $\mathrm{H}_{2} \mathrm{CO} \cdots\left(\mathrm{H}_{2} \mathrm{CO}\right)_{n}$ complexes. The subsequent columns contain the information about the chain length $\mathrm{n}$, the absolute value of the static dipole moment for the whole chain $|\mu|(0)$, the total interaction-induced dipole moment $\Delta|\mu|(0)$ and its contributions: twoand many-body, static polarizability $\alpha_{0}(0)$, the total interaction-induced polarizability $\Delta \alpha_{0}(0)$ and its two- and many-body components, first order hyperpolarizability $\beta_{\mu}(0)$, the total interaction-induced hyperpolarizability $\Delta \beta_{\mu}(0)$ and its two- and many-body components

\begin{tabular}{|c|c|c|c|c|c|c|c|c|c|c|c|c|}
\hline \multirow[t]{2}{*}{$n$} & \multirow[t]{2}{*}{$|\mu|(0)$} & \multicolumn{3}{|l|}{$\Delta|\mu|(0)$} & \multirow[t]{2}{*}{$\alpha_{0}(0)$} & \multicolumn{3}{|l|}{$\Delta \alpha_{0}(0)$} & \multirow[t]{2}{*}{$\beta_{\mu}(0)$} & \multicolumn{3}{|c|}{$\Delta \beta_{\mu}(0)$} \\
\hline & & Total & 2-body & M-body & & Total & 2-body & M-body & & Total & 2-body & M-body \\
\hline \multicolumn{13}{|c|}{$\operatorname{CCSD}(\mathrm{T})$} \\
\hline 1 & 2.0358 & 0.1432 & 0.1432 & - & 34.868 & 0.397 & 0.397 & - & -93.09 & 9.40 & 9.40 & - \\
\hline 2 & 3.1540 & 0.3158 & 0.3027 & 0.0131 & 52.732 & 0.959 & 0.846 & 0.113 & -129.23 & 23.59 & 21.21 & 2.38 \\
\hline 3 & - & - & - & - & - & - & - & - & - & - & - & - \\
\hline 4 & - & - & - & - & - & - & - & - & - & - & - & - \\
\hline \multicolumn{13}{|c|}{ MP2 } \\
\hline 1 & 2.0396 & 0.1418 & 0.1418 & - & 34.901 & 0.391 & 0.391 & - & -71.84 & 12.37 & 12.37 & - \\
\hline 2 & 3.1592 & 0.3131 & 0.2999 & 0.0132 & 52.787 & 0.956 & 0.837 & 0.119 & -95.61 & 29.77 & 27.72 & 2.05 \\
\hline 3 & 4.2881 & 0.4937 & 0.4628 & 0.0309 & 70.728 & 1.577 & 1.297 & 0.280 & -117.49 & 49.05 & 43.62 & 5.43 \\
\hline 4 & 5.4208 & 0.6781 & 0.6277 & 0.0504 & 88.693 & 2.223 & 1.764 & 0.459 & -138.57 & 69.12 & 59.94 & 9.18 \\
\hline \multicolumn{13}{|c|}{ SCF-HF } \\
\hline 1 & 2.4631 & 0.1651 & 0.1651 & - & 33.078 & 0.322 & 0.322 & - & -93.10 & 1.82 & 1.82 & - \\
\hline 2 & 3.8093 & 0.3631 & 0.3492 & 0.0139 & 49.954 & 0.774 & 0.689 & 0.085 & -136.25 & 5.06 & 4.62 & 0.44 \\
\hline 3 & 5.1658 & 0.5713 & 0.5387 & 0.0326 & 66.871 & 1.268 & 1.069 & 0.199 & -178.80 & 8.94 & 7.61 & 1.33 \\
\hline 4 & 6.5265 & 0.7837 & 0.7307 & 0.0530 & 83.805 & 1.780 & 1.455 & 0.325 & -221.06 & 13.11 & 10.68 & 2.43 \\
\hline \multicolumn{13}{|c|}{ B3LYP } \\
\hline 1 & 2.0993 & 0.1527 & 0.1527 & - & 35.794 & 0.439 & 0.439 & - & -127.42 & 6.30 & 6.30 & - \\
\hline 2 & 3.2562 & 0.3371 & 0.3225 & 0.0146 & 54.148 & 1.044 & 0.921 & 0.123 & -176.60 & 23.66 & 16.38 & 7.28 \\
\hline 3 & 4.4231 & 0.5314 & 0.4974 & 0.0340 & 72.557 & 1.707 & 1.416 & 0.291 & -222.09 & 44.70 & 27.14 & 17.56 \\
\hline 4 & 5.5941 & 0.7298 & 0.6743 & 0.0555 & 90.990 & 2.394 & 1.917 & 0.477 & -266.02 & 67.31 & 38.28 & 29.03 \\
\hline \multicolumn{13}{|c|}{ LC-BLYP } \\
\hline 1 & 2.1647 & 0.1557 & 0.1557 & - & 35.829 & 0.444 & 0.444 & - & -94.81 & 10.29 & 10.29 & - \\
\hline 2 & 3.3566 & 0.3437 & 0.3290 & 0.0147 & 54.214 & 1.063 & 0.937 & 0.126 & -129.63 & 27.18 & 23.88 & 3.30 \\
\hline 3 & 4.5587 & 0.5420 & 0.5075 & 0.0345 & 72.656 & 1.743 & 1.445 & 0.298 & -161.90 & 46.63 & 38.19 & 8.44 \\
\hline 4 & 5.7649 & 0.7445 & 0.6882 & 0.0563 & 91.121 & 2.447 & 1.959 & 0.488 & -193.03 & 67.22 & 52.77 & 14.45 \\
\hline \multicolumn{13}{|c|}{ PBE0 } \\
\hline 1 & 2.0949 & 0.1499 & 0.1499 & - & 35.236 & 0.453 & 0.453 & - & -118.82 & 6.06 & 6.06 & - \\
\hline 2 & 3.2476 & 0.3307 & 0.3166 & 0.0141 & 53.308 & 1.068 & 0.950 & 0.118 & -165.99 & 20.86 & 15.13 & 5.73 \\
\hline 3 & 4.4100 & 0.5213 & 0.4882 & 0.0331 & 71.433 & 1.739 & 1.460 & 0.279 & -210.13 & 38.67 & 24.83 & 13.84 \\
\hline 4 & 5.5764 & 0.7158 & 0.6618 & 0.0540 & 89.581 & 2.433 & 1.975 & 0.458 & -252.98 & 57.78 & 34.79 & 22.99 \\
\hline \multicolumn{13}{|c|}{ M06-2X } \\
\hline 1 & 2.1365 & 0.1473 & 0.1473 & - & 34.593 & 0.440 & 0.440 & - & -100.17 & 7.74 & 7.74 & - \\
\hline 2 & 3.3083 & 0.3251 & 0.3114 & 0.0137 & 52.325 & 1.040 & 0.925 & 0.115 & -139.83 & 21.32 & 17.78 & 3.54 \\
\hline 3 & 4.4897 & 0.5125 & 0.4804 & 0.0321 & 70.108 & 1.694 & 1.424 & 0.270 & -177.40 & 37.01 & 28.40 & 8.61 \\
\hline 4 & 5.6750 & 0.7039 & 0.6516 & 0.0523 & 87.913 & 2.369 & 1.928 & 0.441 & -214.09 & 53.56 & 39.11 & 14.45 \\
\hline \multicolumn{13}{|c|}{ CAM-B3LYP } \\
\hline 1 & 2.1713 & 0.1547 & 0.1547 & - & 35.232 & 0.417 & 0.417 & - & -100.59 & 9.14 & 9.14 & - \\
\hline 2 & 3.3655 & 0.3411 & 0.3268 & 0.0143 & 53.288 & 0.999 & 0.880 & 0.119 & -139.12 & 24.75 & 21.29 & 3.46 \\
\hline 3 & 4.5697 & 0.5376 & 0.5040 & 0.0336 & 71.397 & 1.638 & 1.357 & 0.281 & -175.29 & 42.73 & 33.92 & 8.81 \\
\hline 4 & 5.7780 & 0.7382 & 0.6834 & 0.0548 & 89.529 & 2.300 & 1.840 & 0.456 & -210.36 & 61.83 & 46.83 & 15.00 \\
\hline
\end{tabular}


where the first summation includes all the two-body terms $\Delta_{i j} P(1 \ldots n)$, the second one - all the three-body terms $\Delta_{i j k} P(1 \ldots n)$ and the last term $\Delta_{1 \ldots n} P(1 \ldots n)$ contains the n-body interaction contribution.

The relative error of the investigated properties in different methods has been estimated with respect to the $\operatorname{CCSD}(\mathrm{T})$ calculations via:

$\delta[\%]=\frac{\Delta P^{\text {method }}-\Delta P^{C C S D(T)}}{\Delta P^{C C S D(T)}} \cdot 100 \%$.

Similarly, the relative error for the BSSE-uncorrected data has been predicted as:

$B S S E[\%]=\frac{\Delta P^{\text {uncorr }}-\Delta P^{\text {corr }}}{\Delta P^{\text {corr }}} \cdot 100 \%$.

All calculations have been performed with Gamess-US [38] and Gaussian09 [39] program packages with the augcc-pVDZ basis set [40, 41].

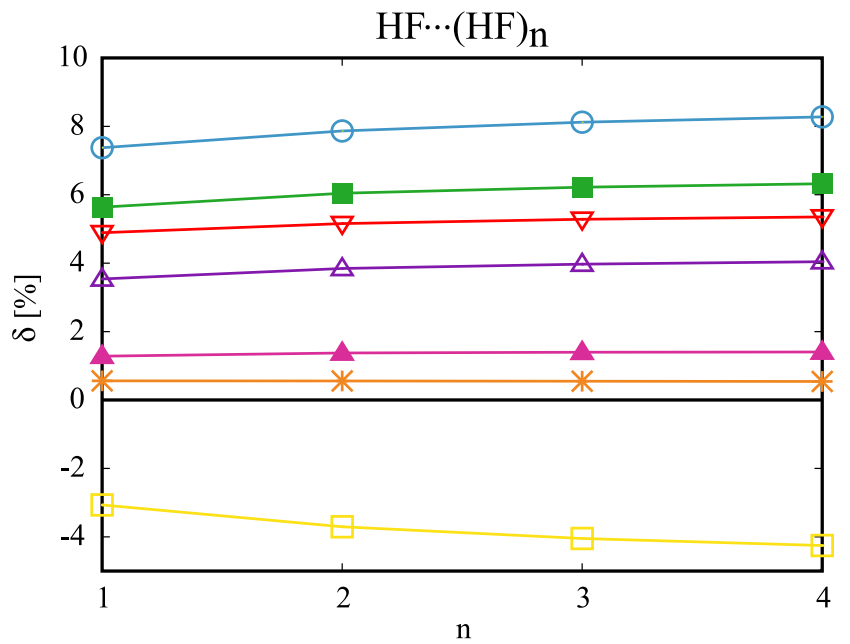

\section{Results and discussion}

Tables 1, 2 and 3 present the values of the electric properties and their interaction-induced contributions for all the investigated systems in different approaches. The corresponding relative errors $(\delta[\%])$ for $\Delta|\mu|(0)$, $\Delta \alpha_{0}(0)$, and $\Delta \beta_{\mu}(0)$ are plotted in Figs. 2, 3 and 4, respectively. For comparison the electric properties of the isolated units ( $\mathrm{HF}, \mathrm{H}_{2} \mathrm{CO}$ and $\mathrm{H}_{3} \mathrm{~N}$ ) are also provided in Table 4.

\section{Dipole moment}

The careful analysis of the gathered data for the interactioninduced dipole moments reveals quite a good performance of the tested DFT functionals. For most cases, the DFT results are of better quality than SCF-HF data. However, the exceptions are observed for linear $\mathrm{HF}$ and $\mathrm{H}_{3} \mathrm{~N} \ldots(\mathrm{HF})_{n}$

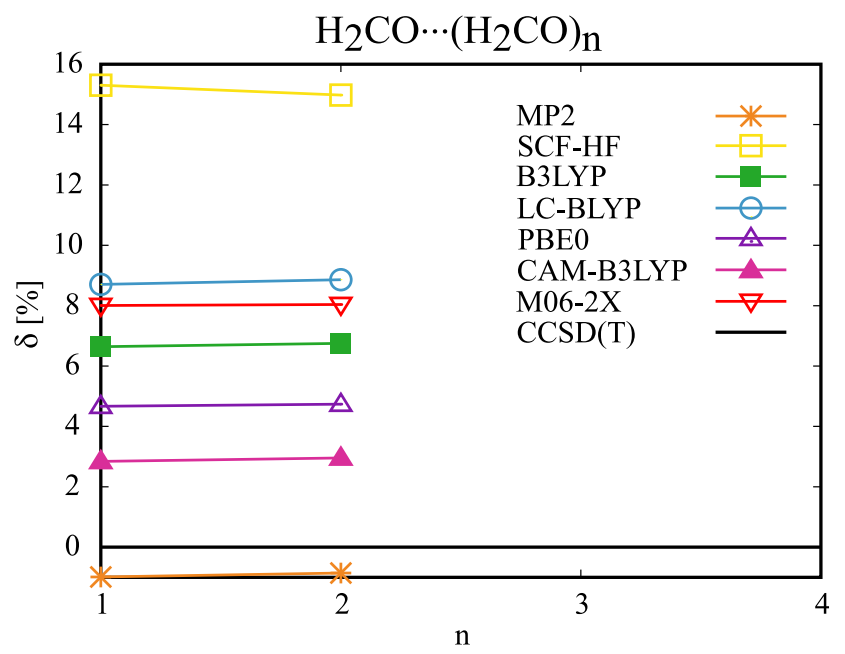

Fig. 2 The percentage relative errors of the approximation applied for estimation of the interaction-induced dipole moment with respect to the $\operatorname{CCSD}(\mathrm{T})$ results 

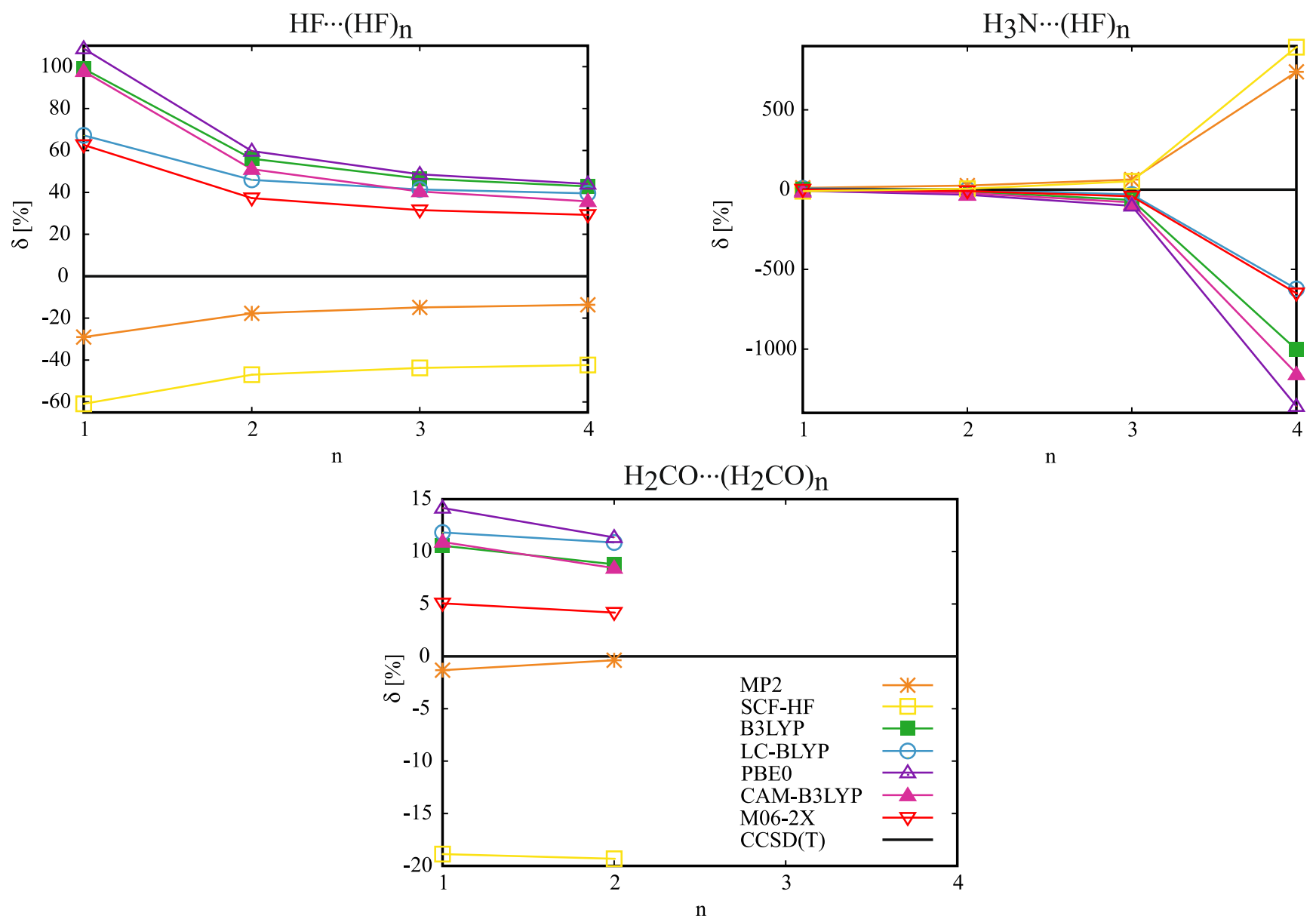

Fig. 3 The percentage relative errors of the approximation applied for estimation of the interaction-induced polarizability with respect to the $\operatorname{CCSD}(\mathrm{T})$ results

chains. In both cases LC-BLYP performs noticeably worse than SCF-HF approach with the relative error almost twice as large for the HF chain. Additionally, for the HF chain also the B3LYP functional and its long-range corrected version CAM-B3LYP demonstrate slight aggravation with respect to the SCF-HF approach. The relative error for the DFT calculations in all the investigated cases does not exceed $9 \%$. The worst data are obtained with LC-BLYP, where the relative errors are between $7.5 \%$ and $8.5 \%$ and the best agreement with the $\operatorname{CCSD}(\mathrm{T})$ interaction-induced dipole moments is observed for the M06-2X functional (errors $1.5 \%-4 \%)$. It is worth mentioning that the relative error for the MP2 calculations does not surpass $1 \%$.

The comparison of the data presented in Fig. 2 shows that the relative error of the interaction-induced dipole moment remains approximately constant with the chain elongation for the $\mathrm{HF}$ and $\mathrm{H}_{2} \mathrm{CO}$ complexes. On the other hand, the lengthening of the $\mathrm{H}_{3} \mathrm{~N} \ldots(\mathrm{HF})_{n}$ system leads to the improvement of the M06-2X and PBE0 results - the errors decrease from $4 \%$ to $2 \%$ and from $6.5 \%$ to $5 \%$, respectively. The opposite behavior is observed for the LC-BLYP data - the results worsen by more than $1 \%$ with increasing chain length.

The decomposition of the total interaction-induced dipole moment for the inspected complexes does not disclose any abrupt demeanor of the DFT results: The quality of the obtained two- and more-body components does not raise many reservations and therefore the DFT functionals tested in this study can be recommended for the many-body analysis of the interaction-induced dipole moment of the investigated complexes.

\section{Polarizability}

Due to the almost negligible non-additivity in the case of the polarizability of the analyzed molecular chains (interactioninduced polarizability less than 1 a.u. for linear chains and less than 2.5 a.u. for formaldehyde complex - below $2.8 \%$ ) the detailed study of the obtained data is omitted. The relative errors for the interaction-induced polarizability are depicted in Fig. 3. For the HF chain the relative error decreases with chain elongation. The dramatic increase of 

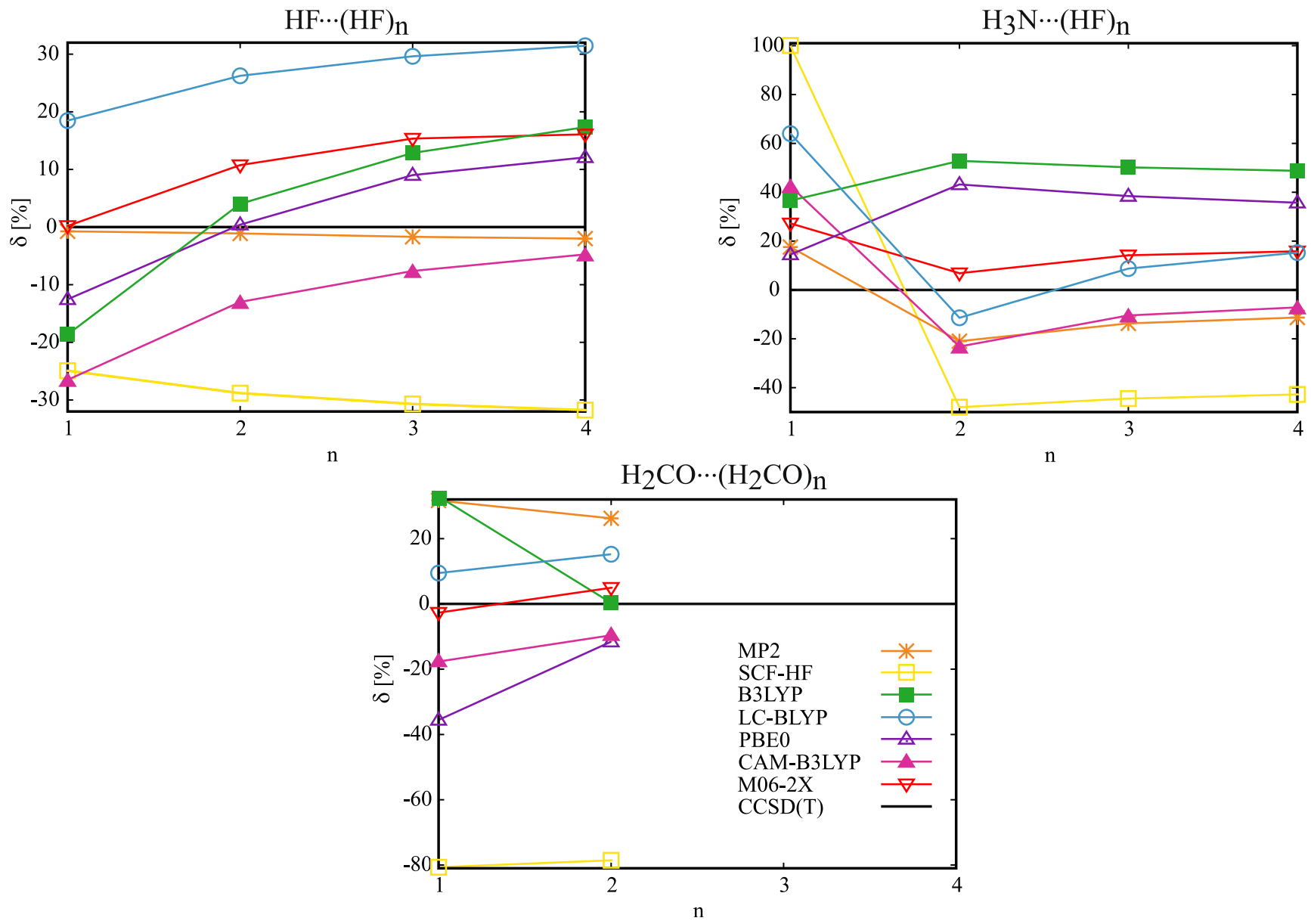

Fig. 4 The percentage relative errors of the approximation applied for estimation of the interaction-induced hyperpolarizability with respect to the $\operatorname{CCSD}(\mathrm{T})$ results

the error for the longest $\mathrm{H}_{3} \mathrm{~N} \ldots(\mathrm{HF})_{n}$ complex should not be taken into account, since the interaction-induced increment for the $\operatorname{CCSD}(\mathrm{T})$ calculations of the five-membered chain accounts for only $0.06 \%$ of the total polarizability value. Therefore, the interaction-induced polarizability within for instance PBE0 approach, that makes up $0.76 \%$ of the total PBE0 polarizability for the longest chain, appears to be in large error with respect to the $\operatorname{CCSD}(\mathrm{T})$ data; however this still gives a very good predictive power for the total polarizability values.

The contribution from many-body terms increases with the chain elongation and for long chains it may exceed the two-body terms [21]. In the case of the $\mathrm{H}_{3} \mathrm{~N} \ldots(\mathrm{HF})_{n}$ complexes, where the two- and many-body terms have opposite signs, the expansion of the chain leads from the negative interaction-induced polarizability that weakens the total response of the system, to the positive $\Delta \alpha_{0}$ for larger number of HF units, where the interaction-induced contribution additionally strengthens the total polarizability of the system. This tendency would be observed for all the investigated methods, however the applied DFT functionals predict the length of the chain for which $\Delta \alpha_{0}$ changes sign as smaller than respective $\mathrm{CCSD}(\mathrm{T}), \mathrm{MP} 2$ or $\mathrm{SCF}$ calculations. In other words, DFT overestimates the many-body terms with respect to the two-body contributions. This is however not a general observation for DFT functionals, since for the HF chains the propensity is opposite: DFT seems to underestimate slightly the many-body terms in comparison to the two-body contributions, and in the case of the $\mathrm{H}_{2} \mathrm{CO}$ chains the agreement between all the applied methods for the ratio of the many-body to two-body contributions to interactioninduced polarizability is very good.

All the calculations lead to the conclusion that again the MP2 method gives good quality results. Additionally, the best-performing DFT functional is CAMB3LYP.

\section{Hyperpolarizability}

According to the author's expectations and experiences [20, 42] the analysis of the DFT functionals assesment appeared to be most complex.

Figure 4 depicts the relative error for the interactioninduced hyperpolarizability. The worst quality results have 
Table 4 The values of the electric properties [a.u.] of analyzed monomers

\begin{tabular}{|c|c|c|c|}
\hline & $\mathrm{HF}$ & $\mathrm{H}_{3} \mathrm{~N}$ & $\mathrm{H}_{2} \mathrm{CO}$ \\
\hline & & $|\mu|(0)$ & \\
\hline $\operatorname{CCSD}(\mathrm{T})$ & 0.7059 & 0.5919 & 0.9470 \\
\hline MP2 & 0.7118 & 0.5999 & 0.9496 \\
\hline SCF-HF & 0.7631 & 0.6350 & 1.1498 \\
\hline B3LYP & 0.7063 & 0.5949 & 0.9740 \\
\hline LC-BLYP & 0.7129 & 0.6249 & 1.0053 \\
\hline PBE0 & 0.7094 & 0.5993 & 0.9733 \\
\hline M06-2X & 0.7168 & 0.6051 & 0.9954 \\
\hline \multirow[t]{2}{*}{ CAM-B3LYP } & 0.7161 & 0.6129 & 1.0090 \\
\hline & & $\alpha_{0}(0)$ & \\
\hline $\operatorname{CCSD}(\mathrm{T})$ & 4.941 & 13.815 & 17.152 \\
\hline MP2 & 4.971 & 13.898 & 17.169 \\
\hline SCF-HF & 4.409 & 12.652 & 16.321 \\
\hline B3LYP & 5.145 & 14.194 & 17.584 \\
\hline LC-BLYP & 5.337 & 14.231 & 17.595 \\
\hline PBE0 & 5.031 & 13.893 & 17.307 \\
\hline M06-2X & 4.856 & 13.542 & 17.005 \\
\hline \multirow[t]{2}{*}{ CAM-B3LYP } & 5.103 & 13.918 & 17.321 \\
\hline & & $\beta_{\mu}(0)$ & \\
\hline $\operatorname{CCSD}(\mathrm{T})$ & -8.89 & -22.24 & -52.11 \\
\hline MP2 & -8.05 & -20.56 & -42.98 \\
\hline SCF-HF & -6.90 & -10.71 & -48.60 \\
\hline B3LYP & -8.72 & -24.55 & -66.95 \\
\hline LC-BLYP & -8.49 & -13.76 & -53.23 \\
\hline PBE0 & -8.18 & -21.45 & -62.74 \\
\hline M06-2X & -6.72 & -15.91 & -54.62 \\
\hline CAM-B3LYP & -8.34 & -17.08 & -55.43 \\
\hline
\end{tabular}

been obtained definitely with the SCF-HF approach - the errors ranging from $25 \%$ to $100 \%$. For the formaldehyde complex the DFT functionals in general perform better than MP2 and the only exception is the PBE0 interaction-induced hyperpolarizability of the dimer. Taking MP2 approach as the suitable method for the incremental values estimation, one can treat its largest error (32\% for the formaldehyde dimer) as an indicator for the satisfactory performance of the DFT functionals. For the linear HF chain all the investigated functionals achieve smaller errors than this limit. In the case of the formaldehyde complexes only PBE0 behaves worse for the dimer. Yet only two functionals lie in this range for the $\mathrm{H}_{3} \mathrm{~N} \ldots(\mathrm{HF})_{n}$ system, namely M06-2X and CAM-B3LYP.

The addition of one unit to the investigated dimers has a significant influence on the quality of the obtained results. With the chain elongation for the HF complexes the relative errors of the DFT interaction-induced hyperpolarizability increase and in the case of PBE0 and B3LYP changes sign for trimer. Similar behavior might be expected for the M06$2 \mathrm{X}$ functional for chains longer than investigated. In other words, these functionals underestimate $\Delta \beta_{\mu}$ for HF dimer and overestimate it for longer chains. The opposite tendency is observed for the $\mathrm{H}_{3} \mathrm{~N}$...(HF $)_{n}$ complex. Here, the dramatic decrease of the relative error value is observed for the LCBLYP, M06-2X and CAM-B3LYP functionals when going from $\mathrm{H}_{3} \mathrm{~N}$...HF to $\mathrm{H}_{3} \mathrm{~N}$...(HF $)_{2}$. However, for longer complexes the error values stabilize. Thus, B3LYP, CAM-B3LYP and PBE0 give the overestimation of $\Delta \beta_{\mu}$ for all the analyzed lengths. LC-BLYP exhibits the underestimation of the $\Delta \beta_{\mu}$ value for the $\mathrm{H}_{3} \mathrm{~N} \ldots(\mathrm{HF})_{2}$ and its overestimation besides. Moreover, M06-2X for three of four investigated $\mathrm{H}_{3} \mathrm{~N} \ldots(\mathrm{HF})_{n}$ complexes underestimates $\Delta \beta_{\mu}$, however its relative errors could be expected to change sign again for the chains longer than investigated. Additionally the correct qualitative description of the total nonlinear response of the HF chain was achived by the DFT calculations, which is in contrary to the SCF-HF results (observe the increase of the $\beta_{\mu}$ to the absolute value).

The decomposition of the interaction-induced hyperpolarizability into the two- and more-body components reveals imperfections of the commonly applied hybrid functionals: B3LYP and PBE0. For all the investigated systems the many-body component calculated with these functionals are of poor quality with respect to the $\operatorname{CCSD}(\mathrm{T})$ reference data. Additionally, for the $\mathrm{H}_{3} \mathrm{~N} \ldots(\mathrm{HF})_{n}$ systems also the two-body terms are not reproduced well. On the other hand, DFT reproduces well the sign change of the two-body terms in the $\mathrm{H}_{3} \mathrm{~N} \ldots(\mathrm{HF})_{n}$ chains with the system elongation. For the many-body terms DFT (and MP2) also predicts the change of sign going from $n=2$ to $n=3$, however this effect is not present in the $\operatorname{CCSD}(\mathrm{T})$ reference results, when all the many-body terms are positive.

Comparison of the ratio of the many-body to the twobody terms in the case of the interaction-induced hyperpolarizability indicates its overestimation for the HF and $\mathrm{H}_{2} \mathrm{CO}$ chains and good correspondence in the case of $\mathrm{H}_{3} \mathrm{~N} \ldots(\mathrm{HF})_{n}$ complexes. Additionally, the mutual relations of the monomer properties and interaction-induced contributions causes the total hyperpolarizability $\beta_{\mu}$ to change signs for shorter $\mathrm{HF}$ and $\mathrm{H}_{3} \mathrm{~N} \ldots(\mathrm{HF})_{n}$ chains within the DFT approaches than within the $\operatorname{CCSD}(\mathrm{T})$ calculations. This observation is consistent with the previously performed analysis for long HF chains [21].

\section{Basis set superposition error}

The estimated BSSE values for the investigated complexes are summarized in Tables 5, 6 and 7. It should be repeated that all the calculations have been carried out with the aug-cc-pVDZ basis set of the medium size. 
Table 5 Interaction-induced electric properties for the hydrogen-bonded linear HF...(HF) $)_{n}$ complexes with and without counterpoise correction and the basis set superposition error [\%]

\begin{tabular}{|c|c|c|c|c|c|c|c|c|c|}
\hline \multirow[t]{2}{*}{$n$} & \multicolumn{3}{|l|}{$\Delta|\mu|(0)$} & \multicolumn{3}{|l|}{$\Delta \alpha_{0}(0)$} & \multicolumn{3}{|l|}{$\Delta \beta_{\mu}(0)$} \\
\hline & CP-cor & CP-uncor & BSSE & CP-cor & CP-uncor & BSSE & CP-cor & CP-uncor & BSSE \\
\hline \multicolumn{10}{|c|}{$\operatorname{CCSD}(\mathrm{T})$} \\
\hline 1 & 0.1730 & 0.1739 & $0.52 \%$ & 0.048 & 0.118 & $145.83 \%$ & 4.32 & 6.10 & $41.20 \%$ \\
\hline 2 & 0.3789 & 0.3807 & $0.48 \%$ & 0.177 & 0.316 & $78.53 \%$ & 11.40 & 15.01 & $31.67 \%$ \\
\hline 3 & 0.5952 & 0.5980 & $0.47 \%$ & 0.334 & 0.540 & $61.68 \%$ & 19.64 & 24.92 & $26.88 \%$ \\
\hline 4 & 0.8159 & 0.8196 & $0.45 \%$ & 0.503 & 0.777 & $54.47 \%$ & 28.37 & 35.28 & $24.36 \%$ \\
\hline \multicolumn{10}{|c|}{ MP2 } \\
\hline 1 & 0.1739 & 0.1746 & $0.40 \%$ & 0.034 & 0.106 & $211.76 \%$ & 4.18 & 5.12 & $22.49 \%$ \\
\hline 2 & 0.3810 & 0.3823 & $0.34 \%$ & 0.146 & 0.288 & $97.26 \%$ & 11.28 & 13.52 & $19.86 \%$ \\
\hline 3 & 0.5985 & 0.6005 & $0.33 \%$ & 0.284 & 0.495 & $74.30 \%$ & 19.31 & 22.75 & $17.81 \%$ \\
\hline 4 & 0.8203 & 0.8231 & $0.34 \%$ & 0.434 & 0.713 & $64.29 \%$ & 27.80 & 32.39 & $16.51 \%$ \\
\hline \multicolumn{10}{|c|}{ SCF-HF } \\
\hline 1 & 0.1677 & 0.1670 & $-0.42 \%$ & 0.019 & 0.075 & $294.74 \%$ & 3.17 & 4.18 & $31.86 \%$ \\
\hline 2 & 0.3648 & 0.3636 & $-0.33 \%$ & 0.094 & 0.206 & $119.15 \%$ & 8.12 & 10.20 & $25.62 \%$ \\
\hline 3 & 0.5711 & 0.5694 & $-0.30 \%$ & 0.188 & 0.354 & $88.30 \%$ & 13.62 & 16.69 & $22.54 \%$ \\
\hline 4 & 0.7812 & 0.7789 & $-0.29 \%$ & 0.290 & 0.511 & $76.21 \%$ & 19.36 & 23.42 & $20.97 \%$ \\
\hline \multicolumn{10}{|c|}{ B3LYP } \\
\hline 1 & 0.1827 & 0.1850 & $1.26 \%$ & 0.096 & 0.167 & $73.96 \%$ & 3.44 & 5.41 & $57.27 \%$ \\
\hline 2 & 0.4018 & 0.4062 & $1.10 \%$ & 0.277 & 0.418 & $50.90 \%$ & 11.86 & 15.66 & $32.04 \%$ \\
\hline 3 & 0.6323 & 0.6389 & $1.04 \%$ & 0.490 & 0.698 & $42.45 \%$ & 22.17 & 27.74 & $25.12 \%$ \\
\hline 4 & 0.8674 & 0.8764 & $1.04 \%$ & 0.718 & 0.993 & $38.30 \%$ & 33.29 & 40.43 & $21.45 \%$ \\
\hline \multicolumn{10}{|c|}{ LC-BLYP } \\
\hline 1 & 0.1857 & 0.1894 & $1.99 \%$ & 0.081 & 0.158 & $95.06 \%$ & 5.00 & 7.65 & $53.00 \%$ \\
\hline 2 & 0.4087 & 0.4159 & $1.76 \%$ & 0.259 & 0.411 & $58.69 \%$ & 14.40 & 19.47 & $35.21 \%$ \\
\hline 3 & 0.6436 & 0.6544 & $1.68 \%$ & 0.472 & 0.696 & $47.46 \%$ & 25.47 & 32.72 & $28.46 \%$ \\
\hline 4 & 0.8834 & 0.8978 & $1.63 \%$ & 0.702 & 0.996 & $41.88 \%$ & 37.30 & 46.63 & $25.01 \%$ \\
\hline \multicolumn{10}{|c|}{ PBE0 } \\
\hline 1 & 0.1791 & 0.1801 & $0.56 \%$ & 0.101 & 0.174 & $72.28 \%$ & 3.69 & 5.23 & $41.73 \%$ \\
\hline 2 & 0.3934 & 0.3954 & $0.41 \%$ & 0.283 & 0.427 & $50.88 \%$ & 11.45 & 14.83 & $29.52 \%$ \\
\hline 3 & 0.6189 & 0.6219 & $0.48 \%$ & 0.497 & 0.709 & $42.66 \%$ & 21.41 & 25.98 & $21.35 \%$ \\
\hline 4 & 0.8488 & 0.8530 & $0.49 \%$ & 0.724 & 1.005 & $38.81 \%$ & 31.80 & 37.72 & $18.62 \%$ \\
\hline \multicolumn{10}{|c|}{ M06-2X } \\
\hline 1 & 0.1752 & 0.1762 & $0.57 \%$ & 0.096 & 0.157 & $63.54 \%$ & 3.09 & 4.47 & $44.66 \%$ \\
\hline 2 & 0.3841 & 0.3860 & $0.49 \%$ & 0.268 & 0.388 & $44.78 \%$ & 9.90 & 12.50 & $26.26 \%$ \\
\hline 3 & 0.6035 & 0.6065 & $0.50 \%$ & 0.469 & 0.648 & $38.17 \%$ & 18.10 & 21.86 & $20.77 \%$ \\
\hline 4 & 0.8273 & 0.8313 & $0.48 \%$ & 0.682 & 0.919 & $34.75 \%$ & 26.96 & 31.83 & $18.06 \%$ \\
\hline \multicolumn{10}{|c|}{ CAM-B3LYP } \\
\hline 1 & 0.1814 & 0.1840 & $1.43 \%$ & 0.079 & 0.148 & $87.34 \%$ & 4.22 & 6.53 & $54.59 \%$ \\
\hline 2 & 0.3984 & 0.4034 & $1.26 \%$ & 0.243 & 0.380 & $56.38 \%$ & 12.63 & 16.87 & $33.57 \%$ \\
\hline 3 & 0.6267 & 0.6342 & $1.20 \%$ & 0.440 & 0.642 & $45.91 \%$ & 22.66 & 28.59 & $26.17 \%$ \\
\hline 4 & 0.8595 & 0.8697 & $1.19 \%$ & 0.650 & 0.917 & $41.08 \%$ & 32.94 & 40.91 & $24.20 \%$ \\
\hline
\end{tabular}

The relative error (BSSE[\%]) arising from the lack of the BSSE correction for the dipole moment is usually smaller than $1 \%$ and only in the case of the linear $\mathrm{HF}$ chain for the LC-BLYP functional it reaches $2 \%$. On these basis one can conclude that the counterpoise procedure has a negligible influence on the quality and quantity of the obtained interaction-induced dipole moment values for the studied complexes. 
Table 6 Interaction-induced electric properties for the hydrogen-bonded $\mathrm{H}_{3} \mathrm{~N} \ldots(\mathrm{HF})_{n}$ complexes with and without counterpoise correction and the basis set superposition error [\%]

\begin{tabular}{|c|c|c|c|c|c|c|c|c|c|}
\hline \multirow[t]{2}{*}{$\mathrm{n}$} & \multicolumn{3}{|l|}{$\Delta|\mu|(0)$} & \multicolumn{3}{|l|}{$\Delta \alpha_{0}(0)$} & \multicolumn{3}{|l|}{$\Delta \beta_{\mu}(0)$} \\
\hline & $\mathrm{CP}-$ cor & CP-uncor & BSSE & $\mathrm{CP}-$ cor & CP-uncor & BSSE & $\mathrm{CP}$-cor & CP-uncor & BSSE \\
\hline \multicolumn{10}{|c|}{$\operatorname{CCSD}(\mathrm{T})$} \\
\hline 1 & 0.4294 & 0.4277 & $-0.40 \%$ & -0.693 & -0.390 & $-43.72 \%$ & -8.38 & -8.22 & $-1.91 \%$ \\
\hline 2 & 0.6948 & 0.6945 & $-0.04 \%$ & -0.436 & -0.057 & $-86.93 \%$ & 14.29 & 14.98 & $4.83 \%$ \\
\hline 3 & 0.9273 & 0.9282 & $0.10 \%$ & -0.214 & 0.236 & $-210.28 \%$ & 29.66 & 31.88 & $7.48 \%$ \\
\hline 4 & 1.1538 & 1.1557 & $0.16 \%$ & -0.021 & 0.497 & $-2466.67 \%$ & 41.19 & 44.88 & $8.96 \%$ \\
\hline \multicolumn{10}{|c|}{ MP2 } \\
\hline 1 & 0.4271 & 0.4251 & $-0.47 \%$ & -0.770 & -0.453 & $-41.17 \%$ & -9.85 & -11.00 & $11.68 \%$ \\
\hline 2 & 0.6930 & 0.6924 & $-0.09 \%$ & -0.545 & -0.153 & $-71.93 \%$ & 11.29 & 10.44 & $-7.53 \%$ \\
\hline 3 & 0.9263 & 0.9267 & $0.04 \%$ & -0.348 & 0.117 & $-133.62 \%$ & 25.60 & 25.90 & $1.17 \%$ \\
\hline 4 & 1.1539 & 1.1552 & $0.11 \%$ & -0.177 & 0.358 & $-302.26 \%$ & 36.53 & 37.85 & $3.61 \%$ \\
\hline \multicolumn{10}{|c|}{ SCF-HF } \\
\hline 1 & 0.3987 & 0.3958 & $-0.73 \%$ & -0.621 & -0.406 & $-34.62 \%$ & -16.77 & -6.11 & $-63.57 \%$ \\
\hline 2 & 0.6446 & 0.6420 & $-0.40 \%$ & -0.459 & -0.188 & $-59.04 \%$ & 7.43 & 8.05 & $8.34 \%$ \\
\hline 3 & 0.8636 & 0.8608 & $-0.32 \%$ & -0.325 & 0.003 & $-100.92 \%$ & 16.47 & 18.17 & $10.32 \%$ \\
\hline 4 & 1.0783 & 1.0752 & $-0.29 \%$ & -0.209 & 0.174 & $-183.25 \%$ & 23.57 & 26.20 & $11.16 \%$ \\
\hline \multicolumn{10}{|c|}{ B3LYP } \\
\hline 1 & 0.4575 & 0.4592 & $0.37 \%$ & -0.721 & -0.405 & $-43.83 \%$ & -11.45 & -10.21 & $-10.83 \%$ \\
\hline 2 & 0.7407 & 0.7450 & $0.58 \%$ & -0.382 & 0.012 & $-103.14 \%$ & 21.84 & 23.06 & $5.59 \%$ \\
\hline 3 & 0.9889 & 0.9956 & $0.68 \%$ & -0.075 & 0.393 & $-624.00 \%$ & 44.54 & 47.37 & $6.35 \%$ \\
\hline 4 & 1.2305 & 1.2396 & $0.74 \%$ & 0.190 & 0.725 & $281.58 \%$ & 61.27 & 65.17 & $6.37 \%$ \\
\hline \multicolumn{10}{|c|}{ LC-BLYP } \\
\hline 1 & 0.4579 & 0.4621 & $0.92 \%$ & -0.750 & -0.468 & $-37.60 \%$ & -13.74 & -11.36 & $-17.32 \%$ \\
\hline 2 & 0.7436 & 0.7519 & $1.12 \%$ & -0.440 & -0.079 & $-82.05 \%$ & 12.66 & 15.70 & $24.01 \%$ \\
\hline 3 & 0.9958 & 1.0078 & $1.21 \%$ & -0.149 & 0.290 & $-294.63 \%$ & 32.25 & 37.06 & $14.91 \%$ \\
\hline 4 & 1.2420 & 1.2577 & $1.26 \%$ & 0.110 & 0.620 & $463.64 \%$ & 47.47 & 54.11 & $13.99 \%$ \\
\hline \multicolumn{10}{|c|}{ PBE0 } \\
\hline 1 & 0.4572 & 0.4552 & $-0.44 \%$ & -0.641 & -0.327 & $-48.99 \%$ & -9.60 & -9.82 & $2.29 \%$ \\
\hline 2 & 0.7346 & 0.7344 & $-0.03 \%$ & -0.297 & 0.094 & $-131.65 \%$ & 20.46 & 20.40 & $-0.29 \%$ \\
\hline 3 & 0.9772 & 0.9783 & $0.11 \%$ & 0.004 & 0.468 & $11600.00 \%$ & 41.06 & 42.10 & $2.53 \%$ \\
\hline 4 & 1.2135 & 1.2158 & $0.19 \%$ & 0.265 & 0.797 & $200.75 \%$ & 55.90 & 58.10 & $3.94 \%$ \\
\hline \multicolumn{10}{|c|}{ M06-2X } \\
\hline 1 & 0.4466 & 0.4461 & $-0.11 \%$ & -0.594 & -0.345 & $-41.92 \%$ & -11.90 & -10.22 & $-14.12 \%$ \\
\hline 2 & 0.7146 & 0.7158 & $0.17 \%$ & -0.286 & 0.024 & $-108.39 \%$ & 10.90 & 12.83 & $17.71 \%$ \\
\hline 3 & 0.9500 & 0.9523 & $0.24 \%$ & -0.016 & 0.355 & $-2318.75 \%$ & 26.41 & 29.42 & $11.40 \%$ \\
\hline 4 & 1.1795 & 1.1831 & $0.31 \%$ & 0.223 & 0.652 & $192.38 \%$ & 38.02 & 42.05 & $10.60 \%$ \\
\hline \multicolumn{10}{|c|}{ CAM-B3LYP } \\
\hline 1 & 0.4493 & 0.4518 & $0.55 \%$ & -0.696 & -0.419 & $-39.80 \%$ & -10.67 & -9.32 & $-12.65 \%$ \\
\hline 2 & 0.7272 & 0.7327 & $0.75 \%$ & -0.396 & -0.046 & $-88.38 \%$ & 15.27 & 17.30 & $13.29 \%$ \\
\hline 3 & 0.9721 & 0.9803 & $0.84 \%$ & -0.124 & 0.297 & $-339.52 \%$ & 33.86 & 37.39 & $10.43 \%$ \\
\hline 4 & 1.2111 & 1.2219 & $0.89 \%$ & 0.116 & 0.601 & $418.10 \%$ & 47.70 & 52.97 & $11.05 \%$ \\
\hline
\end{tabular}

The analysis of the relative BSSE for the linear HF and $\mathrm{H}_{3} \mathrm{~N}$...(HF) ${ }_{n}$ complex is unreasonable due to the very small $\Delta \alpha_{0}$ values. However, for the formaldehyde chains the obtained results become more stable owing to the larger interaction-induced polarizability values than in the case of the remaining systems. Here, the relative BSSE changes from above $40 \%$ for short chains to almost $20 \%$ for longer chains. Nevertheless, again the influence of the interaction-induced 
Table 7 Interaction-induced electric properties for the hydrogen-bonded crystalline $\mathrm{H}_{2} \mathrm{CO} \ldots\left(\mathrm{H}_{2} \mathrm{CO}\right)_{\mathrm{n}}$ complexes with and without counterpoise correction and the basis set superposition error [\%]

\begin{tabular}{|c|c|c|c|c|c|c|c|c|c|}
\hline \multirow[t]{2}{*}{$n$} & \multicolumn{3}{|l|}{$\Delta|\mu|(0)$} & \multicolumn{3}{|l|}{$\Delta \alpha_{0}(0)$} & \multicolumn{3}{|l|}{$\Delta \beta_{\mu}(0)$} \\
\hline & CP-cor & $\mathrm{CP}$-uncor & BSSE & CP-cor & CP-uncor & BSSE & CP-cor & $\mathrm{CP}$-uncor & BSSE \\
\hline \multicolumn{10}{|c|}{$\operatorname{CCSD}(\mathrm{T})$} \\
\hline 1 & 0.1432 & 0.1418 & $-0.98 \%$ & 0.397 & 0.563 & $41.81 \%$ & 9.40 & 11.12 & $18.30 \%$ \\
\hline 2 & 0.3158 & 0.3130 & $-0.89 \%$ & 0.959 & 1.275 & $32.95 \%$ & 23.59 & 27.09 & $14.84 \%$ \\
\hline 3 & - & - & - & - & - & - & - & - & - \\
\hline 4 & - & - & - & - & - & - & - & - & - \\
\hline \multicolumn{10}{|c|}{ MP2 } \\
\hline 1 & 0.1418 & 0.1404 & $-0.99 \%$ & 0.391 & 0.563 & $43.99 \%$ & 12.37 & 14.13 & $14.23 \%$ \\
\hline 2 & 0.3131 & 0.3103 & $-0.89 \%$ & 0.956 & 1.281 & $34.00 \%$ & 29.77 & 33.34 & $11.99 \%$ \\
\hline 3 & 0.4937 & 0.4895 & $-0.85 \%$ & 1.578 & 2.053 & $30.10 \%$ & 49.05 & 54.44 & $10.99 \%$ \\
\hline 4 & 0.6781 & 0.6726 & $-0.81 \%$ & 2.223 & 2.849 & $28.16 \%$ & 69.12 & 76.35 & $10.46 \%$ \\
\hline \multicolumn{10}{|c|}{ SCF-HF } \\
\hline 1 & 0.1651 & 0.1636 & $-0.91 \%$ & 0.322 & 0.436 & $35.40 \%$ & 1.82 & 4.10 & $125.27 \%$ \\
\hline 2 & 0.3631 & 0.3600 & $-0.85 \%$ & 0.774 & 0.992 & $28.17 \%$ & 5.06 & 9.54 & $88.54 \%$ \\
\hline 3 & 0.5713 & 0.5667 & $-0.81 \%$ & 1.268 & 1.588 & $25.24 \%$ & 8.94 & 15.59 & $74.38 \%$ \\
\hline 4 & 0.7837 & 0.7777 & $-0.77 \%$ & 1.780 & 2.202 & $23.71 \%$ & 13.11 & 21.92 & $67.20 \%$ \\
\hline \multicolumn{10}{|c|}{ B3LYP } \\
\hline 1 & 0.1527 & 0.1512 & $-0.98 \%$ & 0.439 & 0.627 & $42.82 \%$ & 6.30 & 6.48 & $2.86 \%$ \\
\hline 2 & 0.3371 & 0.3341 & $-0.89 \%$ & 1.044 & 1.397 & $33.81 \%$ & 23.66 & 24.26 & $2.54 \%$ \\
\hline 3 & 0.5314 & 0.5270 & $-0.83 \%$ & 1.707 & 2.222 & $30.17 \%$ & 44.70 & 45.72 & $2.28 \%$ \\
\hline 4 & 0.7298 & 0.7239 & $-0.81 \%$ & 2.394 & 3.072 & $28.32 \%$ & 67.31 & 68.74 & $2.12 \%$ \\
\hline \multicolumn{10}{|c|}{ LC-BLYP } \\
\hline 1 & 0.1557 & 0.1541 & $-1.03 \%$ & 0.444 & 0.639 & $43.92 \%$ & 10.29 & 11.65 & $13.22 \%$ \\
\hline 2 & 0.3437 & 0.3407 & $-0.87 \%$ & 1.063 & 1.429 & $34.43 \%$ & 27.18 & 30.05 & $10.56 \%$ \\
\hline 3 & 0.5420 & 0.5375 & $-0.83 \%$ & 1.743 & 2.276 & $30.58 \%$ & 46.63 & 51.01 & $9.39 \%$ \\
\hline 4 & 0.7445 & 0.7384 & $-0.82 \%$ & 2.447 & 3.147 & $28.61 \%$ & 67.22 & 73.11 & $8.76 \%$ \\
\hline \multicolumn{10}{|c|}{ PBE0 } \\
\hline 1 & 0.1499 & 0.1484 & $-1.00 \%$ & 0.453 & 0.622 & $37.31 \%$ & 6.06 & 6.66 & $9.90 \%$ \\
\hline 2 & 0.3307 & 0.3278 & $-0.88 \%$ & 1.068 & 1.387 & $29.87 \%$ & 20.86 & 22.25 & $6.66 \%$ \\
\hline 3 & 0.5213 & 0.5170 & $-0.82 \%$ & 1.739 & 2.204 & $26.74 \%$ & 38.67 & 40.85 & $5.64 \%$ \\
\hline 4 & 0.7158 & 0.7101 & $-0.80 \%$ & 2.433 & 3.045 & $25.15 \%$ & 57.78 & 60.74 & $5.12 \%$ \\
\hline \multicolumn{10}{|c|}{ M06-2X } \\
\hline 1 & 0.1473 & 0.1457 & $-1.09 \%$ & 0.440 & 0.584 & $32.73 \%$ & 7.74 & 9.06 & $17.05 \%$ \\
\hline 2 & 0.3251 & 0.3221 & $-0.92 \%$ & 1.040 & 1.311 & $26.06 \%$ & 21.32 & 24.02 & $12.66 \%$ \\
\hline 3 & 0.5125 & 0.5080 & $-0.88 \%$ & 1.694 & 2.088 & $23.26 \%$ & 37.01 & 41.07 & $10.97 \%$ \\
\hline 4 & 0.7039 & 0.6979 & $-0.85 \%$ & 2.369 & 2.888 & $21.91 \%$ & 53.56 & 58.99 & $10.14 \%$ \\
\hline \multicolumn{10}{|c|}{ CAM-B3LYP } \\
\hline 1 & 0.1547 & 0.1533 & $-0.90 \%$ & 0.417 & 0.591 & $41.73 \%$ & 9.14 & 10.26 & $12.25 \%$ \\
\hline 2 & 0.3411 & 0.3384 & $-0.79 \%$ & 0.999 & 1.325 & $32.63 \%$ & 24.75 & 27.16 & $9.74 \%$ \\
\hline 3 & 0.5376 & 0.5335 & $-0.76 \%$ & 1.638 & 2.114 & $29.06 \%$ & 42.73 & 46.42 & $8.64 \%$ \\
\hline 4 & 0.7382 & 0.7328 & $-0.73 \%$ & 2.300 & 2.925 & $27.17 \%$ & 61.83 & 66.77 & $7.99 \%$ \\
\hline
\end{tabular}

BSSE for the total value of the polarizability of the whole complex is negligible and the qualitative picture of the $\Delta \alpha_{0}$ changes with the chain elongation remains the same with or without the counterpoise correction.

The changes of the relative BSSE for the interactioninduced hyperpolarizability are parallel to these observed for the dipole moment, however here the absolute values of the errors decrease from $60 \%$ to $20 \%$ for HF chains and from $20 \%$ to $2 \%$ for formaldehyde chains with the chain elongation. Again, similarly as in the case of dipole moment and polarizability, the counterpoise procedure does not affect much the total qualitative picture. However, it cannot be 
neglected for the correct quantitative description of the interaction-induced hyperpolarizability of the investigated systems $[35,36]$.

\section{Conclusions}

The investigation of the electric properties of the hydrogenbonded dimers [20] has shown that the M06-2X functional performed worst mainly for hyperpolarizability (compare HF dimer). However in the case of longer chains, it presents a serious advantage over any other tested functionals. Therefore, M06-2X appears to be the best for the description of the influence of the mutual interaction on the electric properties in the hydrogen-bonded chains. Similar performance can also be observed for the CAM-B3LYP functional. Although these conclusions were verified in the present contribution only for one basis set of the medium size (aug-cc-pVDZ), they should not differ dramatically for other basis set choices. The ordering of the functionals may vary, however the main conclusion of this work remain unchanged: DFT functionals can be applied succesfully for the investigation of the interaction-induced electric properties. One should however keep in mind that the DFT functional performance can also significantly depend on the nature of the intermolecular interactions and the conventional functionals are known to fail for systems governed by dispersion interaction [43-46].

It is also of importance for the complex systems, that the basis set superposition error in the case of interactioninduced dipole moment and polarizability is negligible. What is more for the first-order hyperpolarizability BSSE only has a noticable qualitative meaning, but the quantitative picture remains the same. This observation allows for instance to save a lot of effort in a rational design of novel materials. Further study on this topic is in progress.

The earlier studies suggest the possibility of estimating the electric properties for the large molecular aggregates based on the accurate description of molecular properties and approximate descripton of the interaction-induced contributions [21, 47]. Current findings allow to expect that calculations of molecular properties on high theory level (MP2 or $\operatorname{CCSD}(\mathrm{T})$ ) supplemented by the interaction-induced increments accounted for in DFT could provide a relatively accurate and cheap alternative for regular post-Hartree-Fock predictions.

\section{Acknowledgements Authors gratefully acknowledge Wrocław Center of Networking and Supercomputing and Academic Computer Centre Cyfronet AGH Kraków for the generous allotment of computer time. \\ Fellowship co-financed by European Union within European Social Fund.}

Open Access This article is distributed under the terms of the Creative Commons Attribution Noncommercial License which permits any noncommercial use, distribution, and reproduction in any medium, provided the original author(s) and source are credited.

\section{References}

1. Matsuzawa N, Dixon DA (1994) Density functional theory predictions of polarizabilities and first- and second-order hyperpolarizabilities for molecular systems. J Phys Chem 98:2545-2554

2. Dixon DA, Matsuzawa N (1994) Density functional study of the structures and nonlinear optical properties of urea. J Phys Chem 98:3967-3977

3. Matsuzawa N, Dixon DA (1992) Local density functional calculations of the polarizability and second-order hyperpolarizability of $\mathrm{C}_{60}$. J Phys Chem 96:6872-6875

4. Senatore G, Subbaswamy KR (1986) Hyperpolarizabilities of closed-shell atoms and ions in the local-density approximation. Phys Rev A 34:3619-3629

5. Casida ME, Jamorski C, Bohr F, Guan J, Salahub DR (1996) Optical properties from density-functional theory. In: Karna SP, Yates AT (eds) Nonlinear optical materials: theory and modelling. ACS Symposium Series, ACS Publication, Washington, DC, pp 145-163

6. Jacob CR, Wesolowski TA, Visscher L (2005) Orbital-free embedding applied to the calculation of induced dipole moments in $\mathrm{CO}_{2} \cdots \mathrm{X}(\mathrm{X}=\mathrm{He}, \mathrm{Ne}, \mathrm{Ar}, \mathrm{Kr}, \mathrm{Xe}, \mathrm{Hg})$ van der Waals complexes. J Chem Phys 123:174104

7. Pecul M, Pawlowski F, Jøergensen P, Kohn A, Hattig C (2006) High-order correlation effects on dynamic hyperpolarizabilities and their geometric derivatives: a comparison with density functional results. J Chem Phys 124:114101

8. Salek P, Helgaker T, Vathras O, Agren H, Jonsson D, Gauss J (2005) A comparison of density-functional-theory and coupled-cluster frequency dependent polarizabilities and hyperpolarizabilities. Mol Phys 103:439-450

9. Cohen AJ, Handy NC, Tozer DJ (1999) Density functional calculations of the hyperpolarizabilities of small molecules. Chem Phys Lett 303:391-398

10. Hammond JR, Govind N, Kowalski K, Autschbach J, Xantheas SS (2009) Accurate dipole polarizabilities for water clusters $n=2-12$ at the coupled cluster level of theory and benchmarking of various density functionals. J Chem Phys 131:214103

11. Shelton DP, Rice JE (1994) Measurements and calculations of the hyperpolarizabilities of atoms and small molecules in the gas phase. Chem Rev 94:3-29

12. Suponitsky KY, Tafur S, Masunov AE (2008) Applicability of hybrid density functional theory methods to calculation of molecular hyperpolarizability. J Chem Phys 129:044109

13. van Gisbergen SJA, Schipper PRT, Gritsenki OV, Baerends EJ, Snijders JG, Champagne B, Kirtman B (1999) Electric Field Dependence of the Exchange-Correlation Potential in Molecular Chains. Phys Rev Lett 83:694-697

14. Champagne B, Perpete EA, Jacquemin D, van Gisbergen SJA, Soubra-Ghaoui C, Robins KA, Kirtman B (2000) Assesment of conventional density functional schemes for computing the dipole moment and (hyper)polarizabilities of push-pull $\pi$-conjugated systems. J Phys Chem A 104:4755

15. Champagne B, Perpete EA, van Gisbergen SJA, Baerends EJ, Snijders JG, Soubra-Ghaoui C, Robins KA, Kirtman B (1998) Assesment of conventional density functional schemes for computing the polarizabilities and hyperpolarizabilities of conjugated oligomers: An ab initio investigation of polyacetylene chains. J Chem Phys 109:10489

16. Chantzisa A, Maroulis G (2011) Interaction-induced electric properties in $\mathrm{Kr}-\mathrm{Ne}$ from ab initio and DFT calculations. Is there a 
discrepancy between theory and experiment for the dipole moment? Chem Phys Lett 507:42-47

17. Haskopoulos A, Maroulis G (2006) Interaction dipole moment in $\mathrm{Rg}-\mathrm{Xe}(\mathrm{Rg}=\mathrm{He}, \mathrm{Ne}, \mathrm{Ar}$ and $\mathrm{Kr})$ heterodiatoms from conventional $\mathrm{ab}$ initio and density functional theory calculations. J Math Chem 40:233-241

18. Haskopoulos A, Xenides D, Maroulis G (2005) Interaction dipole moment, polarizability and hyperpolarizability in the $\mathrm{KrXe}$ heterodiatom. Chem Phys 309:271-275

19. Maroulis G, Haskopoulos A (2002) Interaction induced (hyper) polarizability in Ne...Ar. Chem Phys Lett 358:64-70

20. Zawada A, Kaczmarek-Kędziera A, Bartkowiak W (2011) Assessment of DFT functionals for the calculation of interaction-induced electric properties of molecular complexes. Chem Phys Lett 503:39-44

21. Zawada A, Bartkowiak W (2011) Many-body interactions and the electric response of hydrogen-bonded molecular chains. Comput Theor Chem 967:120-128

22. Baranowska A, Zawada A, Fernandez B, Bartkowiak W, Kędziera D, Kaczmarek-Kędziera A (2010) Interaction-induced electric properties and cooperative effects in model systems. Phys Chem Chem Phys 12:852

23. Becke AD (1993) Density-functional thermochemistry. III. The role of exact exchange. J Chem Phys 98:5648-5652

24. Lee C, Yang W, Parr RG (1988) Development of the Colle-Salvetti correlation-energy formula into a functional of the electron density. Phys Rev B 37:785-789

25. Vosko SH, Wilk L, Nusair M (1980) Accurate spin-dependent electron liquid correlation energies for local spin density calculations: a critical analysis. Can J Phys 58:1200-1211

26. Stephens PJ, Devlin FJ, Chabalowski CF, Frisch MJ (1994) Ab initio calculation of vibrational absorption and circular dichroism spectra using density functional force fields. J Phys Chem 98:11623-11627

27. Vetere V, Adamo C, Maldivi P (2000) Performance of the "parameter free" PBE0 functional for the modeling of molecular properties of heavy metals. Chem Phys Lett 325:99-105

28. Iikura H, Tsuneda T, Yanai T, Hirao K (2001) A long-range correction scheme for generalized-gradient-approximation exchange functionals. J Chem Phys 115:3540-3544

29. Zhao Z, Truhlar DG (2008) The M06 suite of density functionals for main group thermochemistry, thermochemical kinetics, noncovalent interactions, excited states, and transition elements: two new functionals and systematic testing of four M06-class functionals and 12 other functionals. Theor Chem Acc 120:215

30. Yanai T, Tew DP, Handy NC (2004) A new hybrid exchangecorrelation functional using the Coulomb-attenuating method (CAM-B3LYP). Chem Phys Lett 393:51-57

31. Turi L, Dannenberg JJ (1993) Correcting for basis set superposition error in aggregates containing more than two molecules: ambiguities in the calculation of the counterpoise correction. J Phys Chem 97:2488-2490

32. Weng SX, Torrie BH, Powell BM (1989) The crystal structure of formaldehyde. Mol Phys 68:25-31

33. Cohen HD, Roothaan CCJ (1965) Electric dipole polarizability of atoms by the Hartree-Fock method. I Theory for closed-shell systems J Chem Phys 43:S34-S39
34. Kurtz HA, Dudis DS (1998) Quantum mechanical methods for predicting nonlinear optical properties. In: Reviews in computational chemistry, vol 12, Wiley-VCH, pp 241-279

35. Skwara B, Zawada A, Bartkowiak W (2007) On the many-body components of interaction-induced electric properties: linear fluoroacetylene trimer as a case study. Comp Lett 2:175-182

36. Skwara B, Bartkowiak W, Silva DL (2009) On the basis set superposition error in supermolecular calculations of interactioninduced electric properties: many-body components. Theor Chem Acc 122:127-136

37. Wells BH, Wilson S (1983) Van der Waals interaction potentials: Many-body basis set superposition effects. Chem Phys Lett 101:429-434

38. Schmidt MW, Baldridge KK, Boatz JA, Elbert ST, Gordon MS, Jensen JH, Koseki S, Matsunga N, Nguyen KA, Su SJ, Windus TL, Dupuis M, Montgomery JA (1993) GAMESS-US Version: 12 JAN 2009 (R1). J Comput Chem 14:1347-1363

39. Frisch MJ, Trucks GW, Schlegel HB, Scuseria GE, Robb MA, R Cheeseman JR, Scalmani G, Barone V, Mennucci B, Petersson GA, Nakatsuji H, Caricato M, Li X, Hratchian HP, Izmaylov AF, Bloino J, Zheng G, Sonnenberg JL, Hada M, Ehara M, Toyota K, Fukuda R, Hasegawa J, Ishida M, Nakajima T, Honda Y, Kitao O, H Nakai H, Vreven T, Montgomery Jr JA, Peralta JE, Ogliaro F, Bearpark M, Heyd JJ, Brothers E, Kudin KN, Staroverov VN, Kobayashi R, Normand J, Raghavachari K, Rendell A, Burant JC, Iyengar SS, Tomasi J, Cossi M, Rega N, Millam JM, Klene M, Knox JE, Cross JB, Bakken V, Adamo C, Jaramillo J, Gomperts G, Stratmann RE, Yazyev O, Austin AJ, Cammi R, Pomelli C, Ochterski JW, Martin RL, Morokuma K, Zakrzewski VG, Voth GA, Salvador P, Dannenberg JJ, Dapprich S, Daniels AD, Farkas O, Foresman JB, Ortiz JV, Cioslowski J, Fox DJ (20009) Gaussian 09 Revision A.1. Gaussian Inc. Wallingford, CT

40. Dunning TH (1989) Gaussian basis sets for use in correlated molecular calculations. i. the atoms boron through neon and hydrogen. J Chem Phys 90:1007-1023

41. Kendall RA, Dunning TH, Harrison RJ (1992) Electron affinities of the first-row atoms revisited. systematic basis sets and wave functions. J Chem Phys 96:6796-6806

42. Kaczmarek-Kędziera A (2011) Confinement effect on pnitroaniline electronic spectrum and electric properties. J Phys Chem A 115:5210-5220

43. Barone V, Biczysko M, Pavone M (2008) The role of dispersion correction to DFT for modelling weakly bound molecular complexes in the ground and excited electronic states. Chem Phys 346:247-256

44. Krishtal A, Vanommeslaeghe K, Olasz A, Veszprémi T, Van Alsenoy C, Geerlings P (2009) Accurate interaction energies at density functional theory level by means of an efficient dispersion correction. J Chem Phys 130:174101

45. Zhao Z, Truhlar DG (2005) Benchmark databases for nonbonded interactions and their use to test density functional theory. J Chem Theory Comput $1: 415-432$

46. Zhao Z, Truhlar DG (2007) Density functionals for noncovalent interaction energies of biological importance. J Chem Theory Comput 3:289-300

47. Góra RW, Zaleśny R, Zawada A, Bartkowiak W, Skwara B, Papadopoulos MG, Silva DL (2011) Large changes of static electric properties induced by hydrogen bonding: an ab initio study of linear HCN oligomers. J Phys Chem A 115:4691 